\title{
Calorimetric monitoring of the effect of endurance training and testosterone treatment on rat serum denaturation transition
}

\author{
Anna Michnik • Zofia Drzazga • \\ Ewa Sadowska-Krępa · Barbara Kłapcińska
}

Received: 24 October 2013/Accepted: 15 December 2013/Published online: 21 January 2014

(C) The Author(s) 2014. This article is published with open access at Springerlink.com

\begin{abstract}
Differential scanning calorimetry (DSC) was applied to evaluate whether endurance training and/or testosterone treatment affect thermal behavior of rat serum. Thirty-six adolescent male Wistar rats were divided into six groups: three untrained and three trained groups, receiving weekly 0,8 , or $80 \mathrm{mg} \mathrm{kg}-1$ BM of testosterone enanthate (TE) each. Total testosterone was significantly higher in both groups treated with the higher TE dose. The rats' body mass and the levels of serum glucose, uric acid, and free fatty acids were additionally determined. The effect of TE treatment was clearly visible in DSC curves for sedentary rats and much less for trained rats. The differences between averaged endothermic denaturation transitions of serum from sedentary and physically active untreated groups were within an experimental error. A statistically significant increase of the width of peak at its half height and the ratio of excess heat capacity at $75{ }^{\circ} \mathrm{C}$ and in the temperature of peak maximum $\left(C_{\mathrm{p} 75} / C_{\mathrm{pmax}}\right)$ were observed due to TE treatment. The same two parameters were significantly lower for physically active rats. Significantly lower values of the enthalpy of serum denaturation $(\Delta H)$ and the first moment of the transition with respect to the temperature axis $\left(M_{1}\right)$ were observed for endurance-trained than for sedentary rats.
\end{abstract}

\footnotetext{
A. Michnik $(\bowtie) \cdot$ Z. Drzazga

Department of Medical Physics, A. Chełkowski Institute

of Physics, University of Silesia, ul. Uniwersytecka 4,

40-007 Katowice, Poland

e-mail: anna.michnik@us.edu.pl

E. Sadowska-Krępa · B. Kłapcińska

Department of Biochemistry, The Jerzy Kukuczka Academy

of Physical Education in Katowice, ul. Mikołowska 72a,

40-065 Katowice, Poland
}

Keywords Differential scanning calorimetry (DSC) . Protein denaturation - Rat serum - Testosterone treatment

\section{Introduction}

Serum is the specimen of choice for analysis in clinical chemistry. The proteome of serum is an indicator of the condition of the whole organism. Serum contains $60-80 \mathrm{mg}$ of protein $/ \mathrm{mL}$ and various small molecules including salts, lipids, amino acids, and sugars. The concentration range of plasma/serum proteins encompasses at least nine orders of magnitude [1]. The major protein constituents of serum include albumin $\left(35-50 \mathrm{mg} \mathrm{mL}^{-1}\right.$ ), immunoglobulins, transferrin, haptoglobin, and lipoproteins. The thermally induced conformational transitions of proteins can be successfully investigated using differential scanning calorimetry (DSC). Recently, the DSC approach was applied to blood serum studies as a novel tool for disease diagnostics [2-9].

The possibility of DSC application in sport medicine has been also suggested and the effect of physical effort on the serum thermal profile of young male amateur cyclists has been investigated [10]. Here, we explore this approach for studying the effect of endurance training and testosterone treatment on rat serum. Calorimetry has already been applied in studies of newborn rat blood serum after maternal administration of cyclophosphamide, an anticancer chemotherapy drug [11]. However, it should be expected that "a thermodynamic signature" for the serum of adult rats differs from that of a newborn's because a sharp difference has been detected between protein patterns of rat serum samples of newborn and adult animals [12].

The trainability of individuals is related to the testosterone and hormonal parameters associated with this 
hormone, such as the testosterone/sex hormone-binding globulin (SHBG) ratio and the testosterone/cortisol ratio [13]. Exercise training is often combined with anabolic androgen use because the suitable level of circulating testosterone is important for an appropriate anabolic environment. About $60 \%$ of circulating testosterone is strongly bound to SHBG, about $40 \%$ of the hormone is bound to albumin, and only 1-4\% exists as free hormone. The biologically active testosterone includes both the free and albumin-bound fractions because the binding between testosterone and albumin is weak. Despite an increasing knowledge related to the acute and chronic testosterone responses to physical exercise and training, data on the changes in testosterone concentration after endurance and strength training still remain controversial.

Acute physical exercise, due to its increase in oxygen consumption, promotes the increase of the oxygen free radical (OFR) formation. When the OFR production exceeds the tissue's antioxidant ability, the result is oxidative stress. Physical training is able to induce adaptational changes in the body capable of preventing the harmful effects of OFR [14]. It was reported that uric acid (UA) reduces exercise-induced oxidative stress. High UA concentrations could confer protection against free radical activity in vivo [15]. Among other biochemical markers of exercise metabolic effects are glucose, lactate, triglyceride, glycerol, and fatty acids.

The aim of this study was to monitor changes in DSC denaturation profile of rat serum due to endurance training and testosterone treatment. In addition, the relationships between several biochemical markers of exercise metabolic stress and parameters of serum thermal transition were discussed.

\section{Experimental}

Groups of animals

Adolescent male Wistar rats of 90-100-g initial body mass (BM), from the stock of the Mossakowski Medical Research Center (Warsaw, Poland), were used for the study. The rats were housed four to five per cage, at a 12-h light/12-h dark cycle, $22-24{ }^{\circ} \mathrm{C}$ ambient temperature, and $45-65 \%$ relative humidity, and were allowed ad libitum access to standard pellet rat chow and tap water.

Before the start of the study, all rats were run-tested on a motorized rodent treadmill $(3 \times 5 \mathrm{~min}$, with 15 -min breaks) to habituate them to the training and to eliminate rats unwilling to run. The selected rats were randomized between the following groups: untrained controls (UTr, $N=6$ ), untrained rats receiving $8 \mathrm{mg} \mathrm{kg}_{\mathrm{BM}}^{-1}(\mathrm{UTr}+\mathrm{TE} 8$, $N=6)$ or $80 \mathrm{mg} \mathrm{kg}-1$ BM (UTr $+\mathrm{TE} 80, N=6)$ of testosterone enanthate (TE) weekly, endurance-trained steroid- untreated rats $(\operatorname{Tr}, N=6)$, and endurance-trained rats receiving $8 \mathrm{mg} \mathrm{kg}_{\mathrm{BM}}^{-1}$ (UTr $\left.+\mathrm{TE} 8, N=6\right)$ or $80 \mathrm{mg} \mathrm{kg}_{\mathrm{BM}}^{-1}$ $(\operatorname{Tr}+\mathrm{TE} 80, N=6)$ of TE weekly.

Stock TE solution (Testosteronum enanthatum, Jelfa, Poland) was diluted with sesame oil as needed and injected intramuscularly once a week for 6 weeks, alternately into the right or left hindlimb. TE-untreated rats were given the same volume of the oil according to the same schedule.

The study protocol was approved by the First Warsaw Ethical Committee for Animal Experiments of the Polish Academy of Sciences, Warsaw, Poland (Certificate of approval No. 251).

\section{Endurance training}

The rats scheduled for endurance training were exercised on a rodent treadmill (at $0^{\circ}$ inclination) 5 days a week, for 6 weeks. The treadmill speed was $16 \mathrm{~m} \mathrm{~min}^{-1}$ during the first week, was increased by $4 \mathrm{~m} \mathrm{~min}^{-1}$ weekly over the next 3 weeks, and was kept at $28 \mathrm{~m} \mathrm{~min}^{-1}$ for the remaining training sessions. The session duration started at $40 \mathrm{~min}^{\mathrm{day}}{ }^{-1}$ and was increased by 5 min daily during the first 4 weeks; during the last 2 weeks, the rats ran for $60 \mathrm{~min}$ daily at $28 \mathrm{~m} \mathrm{~min}^{-1}[16,17]$. Two days after completion of the training, the rats were euthanized by decapitation.

\section{Serum samples}

Trunk blood was collected, allowed to clot at room temperature, and spun to obtain serum for total testosterone (TT) assays. Serum TT was determined with a radioimmunoassay (KIPI19000, DIASource Immunoassays S.A., Belgium). In addition, the concentrations of serum glucose, uric acid (UA), and free fat acids (FFA) were assessed by enzymatic methods using commercially available diagnostic kits (Randox UK, cat. no. GL 2623, UA 230, and FA 115 , respectively). The mean values in each group are shown in Table 1.

\section{DSC measurements}

Differential scanning calorimetry experiments were carried out on the blood serum obtained from rats belonging to one of the six mentioned groups. Serum samples were stored at $-20{ }^{\circ} \mathrm{C}$ before the analysis. For DSC measurements, the samples were diluted 20-fold in degassed DDW. The $\mathrm{pH}$ of the diluted samples was within the range of 6.5-7.5.

DSC scans were performed using the VP DSC ultrasensitive microcalorimeter (MicroCal Inc., Northampton, MA) with cell volume of $0.5 \mathrm{~mL}$. The samples were heated from $20{ }^{\circ} \mathrm{C}$ to $100{ }^{\circ} \mathrm{C}$ with a scan rate of $1.0{ }^{\circ} \mathrm{C} \mathrm{min}{ }^{-1}$. In addition, a constant pressure of about 1.8 atm was exerted on the liquids in the cells. The calorimetric data were 
Table 1 Effects of testosterone enanthate (TE) treatment and endurance training on body mass (BM), serum total testosterone (TT) glucose, uric acid (UA), and free fatty acids (FFA) levels in male Wistar rats

\begin{tabular}{|c|c|c|c|c|c|c|}
\hline Variable & $\mathrm{UTr}$ & $\mathrm{UTr}+\mathrm{TE} 8$ & $\mathrm{UTr}+\mathrm{TE} 80$ & $\operatorname{Tr}$ & $\operatorname{Tr}+\mathrm{TE} 8$ & $\operatorname{Tr}+$ TE 80 \\
\hline $\mathrm{BM} / \mathrm{g}$ & $328.2 \pm 29.8$ & $319.0 \pm 44.6$ & $264.5^{*} \pm 8.3$ & $297.2 \pm 64.1$ & $297.3 \pm 33.1$ & $264.8 \pm 18.8$ \\
\hline $\mathrm{TT} / \mathrm{nmol} \mathrm{L}^{-1}$ & $2.85 \pm 2.76$ & $2.69 \pm 1.09$ & $30.22^{* * *} \pm 9.24$ & $3.44 \pm 3.14$ & $2.88 \pm 1.76$ & $32.18^{* * * *} \pm 2.59$ \\
\hline Glucose $/ \mathrm{mg} \mathrm{dL}^{-1}$ & $139^{\# \# \#} \pm 13.4$ & $114.7^{\#} \pm 8.1$ & $89.8 \pm 6.9$ & $106.9 \pm 19.8$ & $101.7 \pm 9.2$ & $95.3 \pm 9.5$ \\
\hline $\mathrm{UA} / \mathrm{mg} \mathrm{dL}^{-1}$ & $2.3 \pm 0.4$ & $2.1 \pm 0.5$ & $2.4 \pm 0.5$ & $2.3 \pm 0.5$ & $3.3^{+} \pm 0.8$ & $2.8 \pm 0.7$ \\
\hline $\mathrm{FFA} / \mathrm{mmol} \mathrm{L}^{-1}$ & $0.57 \pm 0.16$ & $0.68 \pm 0.15$ & $0.67 \pm 0.26$ & $0.63 \pm 0.31$ & $0.55 \pm 0.19$ & $0.83 \pm 0.24$ \\
\hline
\end{tabular}

Data are means $( \pm \mathrm{SD})$. UTr untrained rats, Tr endurance-trained rats, TE $8 \mathrm{mg} \mathrm{kg}-1$ BM TE once a week, TE80 $80 \mathrm{mg} \mathrm{kg}-1$ TE once a week; $* p<0.05$ versus the UTr and $\mathrm{UTr}+\mathrm{TE} 8$ group, ${ }^{* *} p=0.01$ versus $\mathrm{Tr}+\mathrm{TE} 8$ group, $* * * p<0.001$ versus the respective untreated and TE $8 \mathrm{mg} \mathrm{kg}$ BM group, ${ }^{-1} p<0.05,{ }^{\# \# \#} p<0.001$ versus $\mathrm{UTr}+\mathrm{TE} 80$ group, ${ }^{+} p<0.05$ versus untreated group (Kruskal-Wallis test)

corrected for the instrumental baseline water-water. DSC curves were normalized for the gram mass of protein and next a linear baseline was subtracted. The curves of apparent excess heat capacity, $C_{\mathrm{p}}^{\mathrm{ex}}$, versus temperature were plotted. Protein concentrations were determined according to its amount in dry mass of the serum sample.

Analysis

DSC curves were analyzed with the use of MicroCal Origin software. The following thermodynamic parameters have been found: the temperature of peak maximum $\left(T_{\mathrm{m}}\right)$, the enthalpy of serum denaturation $(\Delta H)$ (calculated as the area under the peak), the width of peak in its half height (HHW), and the normalized first moment $\left(M_{1}\right)$ of the thermal transition with respect to the temperature axis calculated as

$M_{1}=\frac{\int_{T_{\mathrm{i}}}^{T_{\mathrm{f}}} T C_{\mathrm{p}} \mathrm{d} T}{\int_{T_{\mathrm{i}}}^{T_{\mathrm{f}}} C_{\mathrm{p}} \mathrm{d} T}$

where $T_{\mathrm{i}}$ and $T_{\mathrm{f}}$ are the beginning and the end of denaturation, respectively. In addition, the ratios $C_{\mathrm{p} 75} / C_{\mathrm{pmax}}$ (where $C_{\mathrm{p} 75}$ is the value of $C_{\mathrm{p}}^{\mathrm{ex}}$ at $75{ }^{\circ} \mathrm{C}$ (the approximate temperature of the shoulder) and $C_{\mathrm{pmax}}$ the value of $C_{\mathrm{p}}^{\mathrm{ex}}$ at $T_{\mathrm{m}}$ ) were calculated.

Statistical analysis of the results was done with Statistica 10 using ANOVA, the U Mann-Whitney, or Kruskal-Wallis tests. The Shapiro-Wilk and the Levene tests were used to check the normality of the distributions and homogeneity of the variance, respectively. The significance of betweengroup differences was tested using a 2-way ANOVA, with training status and TE dose as the main factors, followed by the post hoc Tukey's HSD (honestly significant difference) test. In all cases, $p<0.05$ was considered significant.

\section{Results and discussion}

The averaged DSC serum curve for the untrained control group of rats is shown in Fig. 1. The shaded area represents

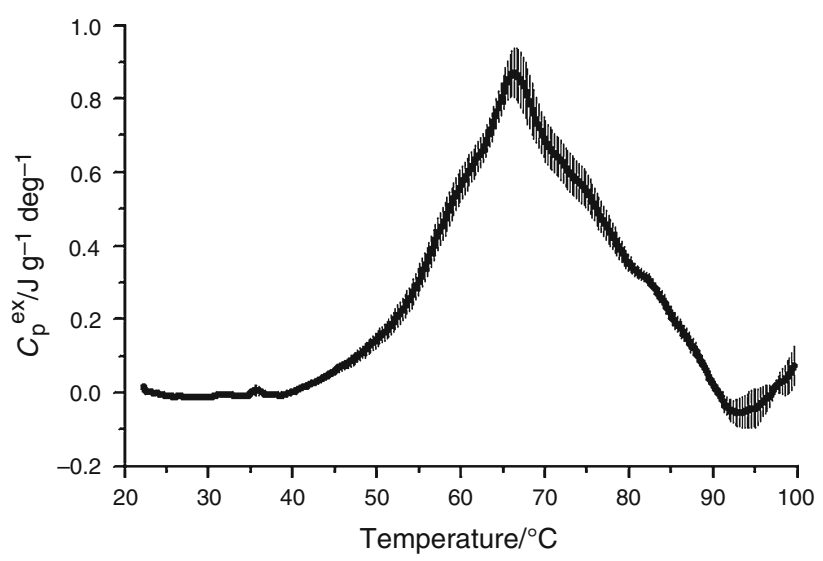

Fig. 1 Mean serum DSC curve $(n=6)$ of rats from untrained control group. The shaded area is the standard error of the mean at each temperature

the standard error of the mean at each temperature. The complex endothermic transition observed in the temperature range $40-90{ }^{\circ} \mathrm{C}$ arises from the unfolding of proteins within the serum. Each individual protein has a unique thermal profile under certain experimental conditions. The peak representing serum denaturation is formed as the weighted sum of thermal profiles of constituent proteins, but the overall shape of the denaturation peak may be modified by binding interactions and environmental factors [18].

In general, there are some similarities between denaturation DSC profiles of rat serum and human plasma/ serum of healthy individuals [2-6]. The temperature range of the whole transition is practically the same; however, the endothermic peak is more symmetric for rat than for human serum. The rat DSC profile (Fig. 1) is surprisingly simple and component transitions are not well resolved. The major transition represented by a clear peak with $T_{\mathrm{m}}$ ca. $66{ }^{\circ} \mathrm{C}$ is not as sharp as that observed at ca. $62{ }^{\circ} \mathrm{C}$ for human serum [2-7]. Two shoulders at about $75^{\circ} \mathrm{C}$ and $82-83{ }^{\circ} \mathrm{C}$ are barely visible in Fig. 1. It is not clear which rat serum proteins contribute to the major transition and shoulders. 


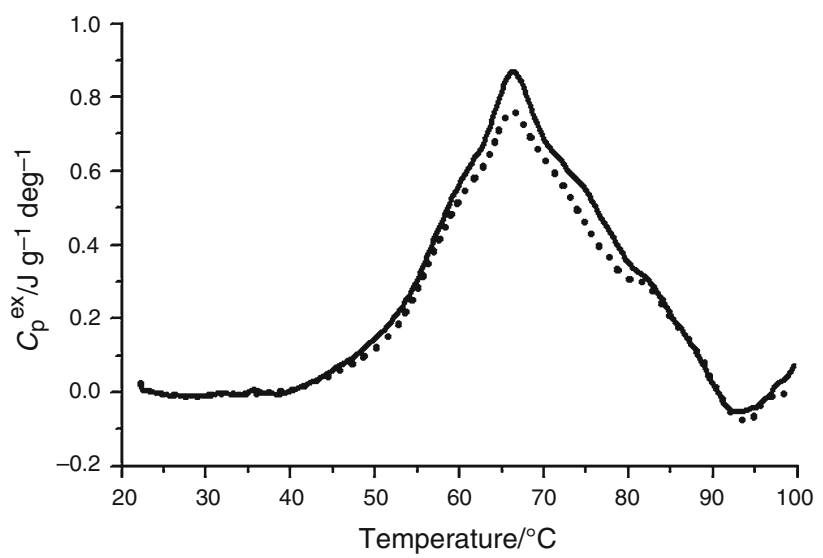

Fig. 2 The comparison of averaged DSC curves of serum for rats from untrained (solid line) and endurance-trained (dot line) steroiduntreated groups

DSC curves of individual proteins in human plasma, useful in the analysis of plasma or serum transition, have been presented by Garbett et al. [2], but for rat proteins there is no corresponding set of data. Notwithstanding this, some analogies seem to be possible.

The main protein fractions of human as well as rat blood serum are albumins and globulins. A detailed investigation of rat serum proteome by Gianazza et al. [12] shows, however, that the protein assortment in rat serum is definitely different from that in human serum. Some proteins are present in much lower concentration in rat than in human serum (e.g., orosomucoid or $\alpha_{1}$-acidic glycoprotein and haptoglobin under physiologic conditions), while others are present in much higher concentration (e.g., C-reactive protein); some proteins are species specific to the rat. Even common proteins display different physico-chemical parameters [12]. The denaturation behavior of albumin, the most abundant serum protein, depends on the species. Significant differences have been reported with respect to the conformational stability and the mechanism of the unfolding pathway for mammalian albumin $[19,20]$. The calorimetric enthalpy as well as thermal denaturation temperature has been shown lower for rat than for human and bovine defatted albumin [19]. It should also be noted that the transition temperatures for fatty acids free albumins are lower than for their non-defatted counterparts [20].

Fig. 2 compares the averaged DSC curves of blood serum for rats from the untrained and endurance-trained steroid-untreated groups. These mean curves are very similar. The slight decrease of transition peak intensity seems to be within the experimental error. However, a distinct feature of serum transition observed for the $\mathrm{Tr}$ group is the lack of the shoulder at $75{ }^{\circ} \mathrm{C}$.

The effect of testosterone treatment on the serum denaturation transition is shown in Fig. 3 and 4 for the untrained and endurance-trained group, respectively. A

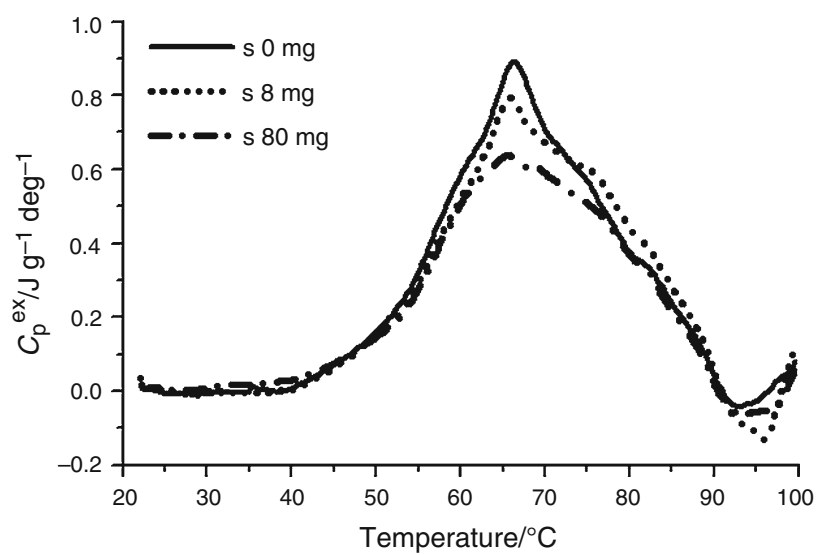

Fig. 3 The averaged serum DSC curves for rats from UTr, $\mathrm{UTr}+\mathrm{TE} 8$, and UTr + TE80 groups

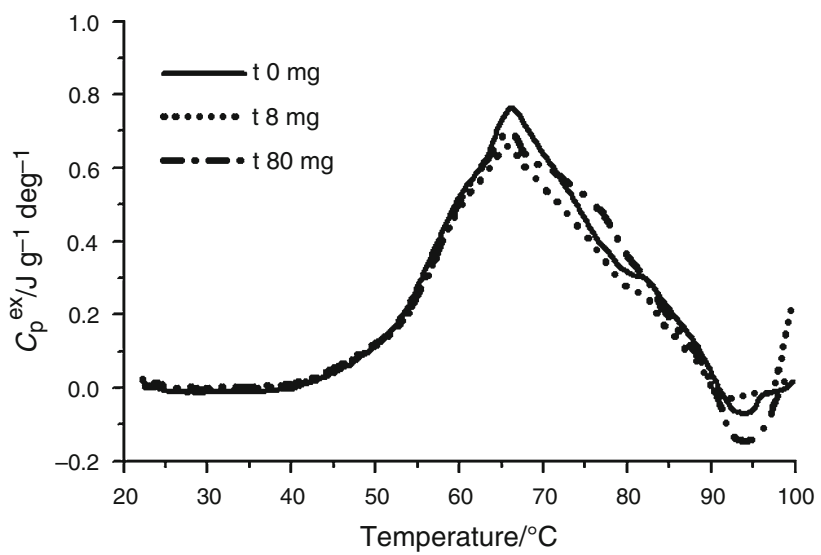

Fig. 4 The averaged serum DSC curves for rats from $\mathrm{Tr}$, $\mathrm{Tr}+\mathrm{TE}$, and $\mathrm{Tr}+\mathrm{TE} 80$ groups

decrease of intensity and a broadening of the thermal transition peak with increasing of testosterone dose can be seen. It is interesting that these effects are more clearly visible in the group of untrained rats. Additionally, for TEtreated sedentary rats, the shoulder at about $75^{\circ} \mathrm{C}$ is well visible (Fig. 3). Surprisingly, the intensity of the averaged DSC curve for the serum from trained rats treated with the higher testosterone dose $(\mathrm{Tr}+\mathrm{TE} 80)$ seems to be more similar to the intensity of the thermal curve received for the steroid-untreated group ( $\mathrm{Tr})$ than for that treated with a lower TE dose ( $\mathrm{Tr}+\mathrm{TE} 8)$. For the $\mathrm{Tr}+\mathrm{TE} 80$, but not for the $\mathrm{Tr}+\mathrm{TE} 8$ group, the shoulder in the $75-80{ }^{\circ} \mathrm{C}$ temperature range occurs (Fig. 4).

Such results suggest that the effects of testosterone treatment and physical activity may be antagonistic to each other. Recently, similar antagonistic effects of testosterone and physical activity on muscle fiber diameter in rats were reported [21].

The comparison of thermodynamic parameters summarized in Table 2 suggests that there are no significant 
Table 2 Effects of testosterone enanthate (TE) treatment and endurance training on thermodynamic parameters of serum denaturation transition

\begin{tabular}{lcccrrr}
\hline Variable & \multicolumn{1}{c}{$\mathrm{UTr}$} & $\mathrm{UTr}+\mathrm{TE} 8$ & $\mathrm{UTr}+\mathrm{TE} 80$ & $\mathrm{Tr}$ & $\mathrm{Tr}+\mathrm{TE} 8$ & $\mathrm{Tr}+\mathrm{TE} 80$ \\
\hline$T_{\mathrm{m}} /{ }^{\circ} \mathrm{C}$ & $66.2 \pm 0.6$ & $65.8 \pm 0.4$ & $65.4 \pm 1.0$ & $66.4 \pm 1.3$ & $65.5 \pm 0.6$ & $65.9 \pm 0.4$ \\
$\Delta H / \mathrm{J} \mathrm{g}^{-1}$ & $18.8 \pm 3.4$ & $18.8 \pm 2.5$ & $16.9 \pm 1.8$ & $16.7 \pm 1.9$ & $15.2 \pm 1.8$ & $16.5 \pm 1.4$ \\
$\mathrm{HHW} /{ }^{\circ} \mathrm{C}$ & $20.1^{* *} \pm 1.5$ & $23.4 \pm 3.2$ & $26.1 \pm 1.8$ & $19.5 \pm 3.1$ & $22.1 \pm 3.1$ & $23.4 \pm 2.0$ \\
$M_{1} /{ }^{\circ} \mathrm{C}$ & $68.0 \pm 0.7$ & $68.1 \pm 0.6$ & $68.8 \pm 0.8$ & $67.7 \pm 0.9$ & $67.5 \pm 0.6$ & $67.9 \pm 0.6$ \\
$C_{\mathrm{p} 75} / C_{\mathrm{pmax}}$ & $0.62^{* *} \pm 0.04$ & $0.75^{*} \pm 0.12$ & $0.80 \pm 0.08$ & $0.57^{* *} \pm 0.08$ & $0.64 \pm 0.07$ & $0.75 \pm 0.09$ \\
\hline
\end{tabular}

Data are means $\left( \pm\right.$ SD). UTr untrained rats, Tr endurance-trained rats, TE $8 \mathrm{mg} \mathrm{kg}_{\mathrm{BM}}^{-1}$ TE once a week, TE80 $80 \mathrm{mg} \mathrm{kg}-1$ TE once a week; $* p<0.05$ and $* * p<0.005$ versus the respective TE $80 \mathrm{mg} \mathrm{kg}_{\mathrm{BM}}^{-1}$ group (post hoc Tukey test)

differences between the transition temperatures $T_{\mathrm{m}}$ for various subgroups. The results presented in this table indicate that the $H H W$ and $C_{\mathrm{p} 75} / C_{\mathrm{pmax}}$ ratio have been increased by $\mathrm{TE}$ treatment and decreased by endurance training. Two-way ANOVA has revealed that these effects are statistically significant (for both parameters, $p<0.001$ in the case of TE treatment factor and $p<0.05, p<0.01$ for HHW and $C_{\mathrm{p} 75} / C_{\mathrm{pmax}}$ values, respectively, in the case of endurance training factor). No significant interactions between these factor effects have been found. The Tukey post hoc test for $C_{\mathrm{p} 75} / C_{\mathrm{pmax}}$ ratio has yielded significant differences between TE-untreated rats and those receiving the higher TE dose both in the sedentary and trained groups. For the $H H W$ parameter, essential difference has been obtained between the UTr and UTr + TE80 groups. Additionally, the results of statistical analysis indicated significantly lower values of $\Delta H$ as well as $M_{1}$ for the endurance-trained in comparison with sedentary rats ( $p=0.004$ and $p=0.009$, respectively). No significant effect of TE dose on these values was observed.

Statistical correlations found between some biochemical and thermodynamic parameters, presented in Tables 1 and 2 , may be helpful in the explanation of DSC results. The positive moderate correlation between FFA level and $C_{\mathrm{p} 75} /$ $C_{\text {pmax }}$ ratio $(r=0.48, p=0.001)$ suggests a relationship between the appearance of the shoulder at about $75^{\circ} \mathrm{C}$ and the level of fatty acids in serum. A migration of fatty acids, their release or binding to albumin, changes the protein thermal profile of denaturation. As albumin is the most abundant serum protein, the DSC profile of serum should depend highly on denaturation transition of albumin, and hence on the ratio of fatty acid free albumin and fatty acidcarrying albumin fractions. The DSC denaturation transition for the albumin with bound fatty acids is strongly shifted to the higher temperature in relation to the defatted albumin [20, 22]. Thus, a decrease of fatty acid free (defatted) fraction of albumin should lead to a reduction of the main peak intensity. On the other hand, an increase in the number of albumin molecules with bound fatty acids (fatty acid carrying fraction) should cause an increase of peak intensity in the higher temperature range, above the transition temperature. Therefore, the total effect can be seen as a broadening of DSC serum denaturation peak and an increase of $\mathrm{HHW}$ and $C_{\mathrm{p} 75} / C_{\mathrm{pmax}}$ values. Just such an effect has been observed with the TE dose increase in our study. The results shown in Table 1 indicate a significantly

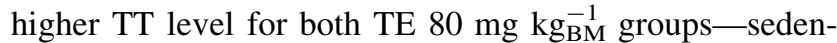
tary and endurance-trained. However, the FFA level was slightly higher only in the Tr + TE80 group.

It is well established that free fatty acids in blood serum are mainly derived from the breakdown of body fat stores, which can be mobilized by catecholamines and exercise. Hydrolysis of the intracellular TG is regulated by hormonesensitive lipase (HSL), the enzyme expressed in adipose tissue, in cardiac and skeletal muscle cells, preferentially in oxidative fibers [23]. Langfort et al. [24] have reported that testosterone may increase HSL activity, thus mobilizing cellular TG stores, while carbohydrate oxidation is diminished. Circulating FFAs are known to reach a maximum shortly after the cessation of exercise, which is a consequence of their augmented release into the plasma pool during exercise, subsequently followed by augmented removal of FFA during the recovery [25]. This may most likely explain why the FFA level in serum samples collected after complete recovery from trained rats given the lower TE dose was moderately lower than in any other group of animals. Unfortunately, any significant differences have not been found between FFA levels in the various rat groups (Table 1). A slightly suppressed level of $T T$ in the group of trained rats treated with a lower TE dose ( $8 \mathrm{mg} \mathrm{kg}-1$ BM $)$ as compared to trained, steroid-untreated controls might result from exogenous administration of TE, which is known to induce suppression of endogenous testosterone [26, 27]. Notably, for this group, a disappearance of a shoulder at about $75^{\circ} \mathrm{C}$ on the DSC curve was observed.

The relationship between FFA and TT levels seems to be complicated and changed by a physical activity. In our experiment, a moderate positive correlation $(r=0.49$, $p=0.02$ ) was found between FFA and TT values for 
endurance-trained rats, but not for untrained animals. Likewise, the statistically significant, positive correlations between $F F A$ level and such thermodynamic parameters as $\Delta H(r=0.50, p=0.02)$, HHW $(r=0.49, p=0.02)$, and $M_{1}(r=0.49, p=0.02)$ were recorded for the trained, but not for the untrained groups. No significant correlation between the above-mentioned parameters and TT levels in trained rats were found.

It is interesting that body mass $B M$ was negatively and $T T$ level was positively correlated with HHW $(r=-0.47$, $p=0.003$ and $r=0.48, p=0.002$, respectively). However, it is not clear which of these correlations can indicate potential causal relationships. There is an important relationship between BM and serum TT level. The significant negative correlation between these variables shown in a previous investigation [28] has been confirmed by the results of our current study $(r=-0.52, p<0.001)$.

The glucose level (see Table 1) has been markedly decreased by both studied factors: endurance training $(p<0.005)$ and by TE treatment $(p<0.001)$. However, for TE treatment effect, the differences between the trained groups have been found not statistically significant. In addition, the mean glucose level for rats receiving $80 \mathrm{mg} \mathrm{kg}-1$ BM was very similar in the sedentary and trained groups. A negative correlation $(r=-0.64, p=0.001)$ between the glucose level and $C_{\mathrm{p} 75} / C_{\mathrm{pmax}}$ ratio occurs for untrained and also for trained rats. For untrained, but not for trained rats, significant negative correlations have been obtained between the glucose level and HHW $(r=-0.76$, $p<0.001)$, as well as between the glucose level and $M_{1}$ $(r=-0.42, p=0.046)$.

High UA concentrations are associated with increased serum antioxidant capacity and reduced oxidative stress during acute physical exercise in healthy subjects [15]. In our experiment, the level of uric acid (UA) varied slightly among different groups of rats (see Table 1). There was no difference among the untreated groups of rats (UTr and Tr). However, the U Mann-Whitney test revealed significantly higher UA level for the trained, compared to the untrained rats $(p=0.01)$. It is in agreement with the finding that the extended acute exercise is associated with a temporary increase of uric acid produced when a relatively high exercise intensity and a high rate of energy consumption trigger activation of adenylate kinase and AMP signaling networks to insure cellular energy homeostasis $[14,29,30]$. The highest value of UA was recorded for the Tr + TE8 group. The significant difference between the $\mathrm{Tr}+\mathrm{TE} 8$ and $\operatorname{Tr}$ groups was found $(p=0.01)$ and no effect of TE treatment on $U A$ level was observed in the sedentary group. It is intriguing that a relatively high positive correlation was found between UA level and $M_{l}(r=0.71, p=0.001)$ for untrained, but not for trained rats.

\section{Conclusions}

The effects of chronic treatment with supraphysiological TE doses, given alone or in combination with moderate intensity endurance training, on rat serum denaturation transition were studied using DSC. Significantly higher serum total testosterone levels were recorded only in both trained and untrained groups given the higher TE dose. A decrease of intensity and a broadening of the thermal transition peak with increasing doses of exogenous testosterone were observed in the untrained groups of animals. For trained rats, the analogous tendency was not so clear, probably due to some kind of antagonistic effects of testosterone and exercise training on serum composition, protein conformational changes, or protein-protein and protein-ligand interactions within the rat serum. Opposite effects of testosterone treatment and training on some transition parameters, such as $H H W$ and $C_{\mathrm{p} 75} / C_{\mathrm{pmax}}$ ratio, were observed. Endurance training was associated with statistically significant decrease, while TE treatment with an increase in $H H W$ and $C_{\mathrm{p} 75} / C_{\mathrm{pmax}}$ ratio. The results of statistical analysis performed for all groups showed that values of the enthalpy of transition, $\Delta H$, and the first moment temperature, $M_{1}$, were also lower for the trained in comparison with untrained rats. The first moment temperature was reported as a very useful parameter in disease diagnosis based on serum DSC studies [2-6]. Lower $M_{1}$ values for healthy individuals and an increase of $M_{1}$ with the severity of the disease were observed. Lower $M_{1}$ values for trained rats suggest their better health status compared to their sedentary counterparts.

A significant relationship was found between the level of free fatty acids in serum and an increase in the intensity of the shoulder at about $75^{\circ} \mathrm{C}$ (positive correlation between FFA and $C_{\mathrm{p} 75} / C_{\mathrm{pmax}}$ ratio). Moderate positive correlations between FFA level and such thermodynamic parameters as $\Delta H, \mathrm{HHW}$, and $M_{1}$ were shown for the trained, but not for sedentary (untrained) rats. Just for endurance-trained rats, moderate positive correlation between serum FFA and TT levels was present. Glucose level, decreased by endurance training and due to TE administration, was negatively correlated with $C_{\mathrm{p} 75} / C_{\mathrm{p} \max }$ ratio. For sedentary rats, negative correlations were observed between the glucose level and HHW or $M_{1}$ and relatively high positive correlation between $U A$ level and $M_{1}$. The interpretation of these interesting results is not entirely clear-cut at present and remains to be validated with a larger group of rats in future investigations.

Open Access This article is distributed under the terms of the Creative Commons Attribution License which permits any use, distribution, and reproduction in any medium, provided the original author(s) and the source are credited. 


\section{References}

1. Adkins JN, Varnum SM, Auberry KJ, Moore RJ, Angell NH, Smith RD, Springer DL, Pounds JG. Toward a human blood serum proteome. Mol Cell Proteomics. 2002;1:947-55.

2. Garbett NC, Miller JJ, Jenson AB, Chaires JB. Calorimetry outside the box: a new window into the plasma proteome. Biophys J. 2008;94:1377-83.

3. Garbett NC, Mekmaysy CS, Helm W, Jenson AB, Chaires JB. Differential scanning calorimetry of blood plasma for clinical diagnosis and monitoring. Exp Mol Pathol. 2009;86:186-91.

4. Michnik A, Drzazga Z, Michalik K, Barczyk A, Santura I, Sozańska E, Pierzchała W. Differential scanning calorimetry study of blood serum in chronic obstructive pulmonary disease. J Therm Annal Calorim. 2010;102:57-60.

5. Todinova S, Krumova S, Gartcheva L, Robeerts Ch, Taneva SG. Microcalorimetry of blood serum proteome: a modified interaction network in the multiple myeloma case. Anal Chem. 2011;83:7992-8.

6. Todinova S, Krumova S, Kurtev P, Dimitrov V, Djongov L, Dudunkov Z, Taneva SG. Calorimetry-based profiling of blood plasma from colorectal cancer patients. Biochim Biophys Acta. 2012;1820:1879-85.

7. Fekecs T, Zapf I, Ferencz A, Lörinczy D. Differential scanning calorimetry (DSC) analysis of human plasma in melanoma patients with or without regional lymph node metastases. J Therm Anal Calorim. 2012;108:149-52.

8. Lörinczy D, editor. Thermal analysis in medical application. Akadémiai Kiadó: Budapest; 2011.

9. Moezzi M, Fekecs T, Zpf I, Ferencz A, Lőrinczy D. Differential scanning calorimetry (DSC) analysis of human plasma in different psoriasis stages. J Therm Anal Calorim. 2013;111:1801-4.

10. Michnik A, Drzazga Z, Poprzęcki S, Czuba M, Kempa K, Sadowska-Krępa E. DSC serum profiles of sportsmen. J Therm Anal Calorim. 2013;113:365-70.

11. Drzazga Z, Michalik K, Hałat T, Michnik A, Trzeciak HI. Calorimetric and spectroscopic studies characterization of newborn rat' blood serum after maternal administration of cyclophosphamide. J Therm Anal Calorim. 2010;102:143-8.

12. Gianazza E, Eberini I, Villa P, Fratelli M, Pinna Ch, Wait R, Gemeiner M, Miller I. Monitoring the effects of drug treatment in rat models of disease by serum protein analysis. J Chromatogr B. 2002;771:107-30.

13. Cadore EL, Kruel LFM. Sex hormones, chapter 13 "Acute and chronic testosterone responses to physical exercise and training". Edited by Raghvendra K. Dubey, ISBN: 978-953-307-856-4, February 8, 2012, DOI: 10.5772/27618. Available from: http:// www.intechopen.com/books/sex-hormones/acute-and-chronic-tes tosterone-responses-to-physical-exercise-and-training.

14. Cunha GS, Ribeiro JL, Oliveira AR. Overtraining: theories, diagnosis and markers. Rev Bras Med Esporte. 2006;12:267-71.

15. Waring WS, Convery A, Mishra V, Shenkin A, Webb DJ, Maxwell SRJ. Uric acid reduces exercise-induced oxidative stress in healthy adults. Clin Sci. 2003;105:425-30.
16. Langfort J, Budohoski L, Newsholme EA. Effect of various types of acute exercise and exercise training on 5,-nucleotidase and adenosine deaminase activities in rat heart: influence of a single bout of endurance exercise. Biochem Mol Med. 1996;59(1): $28-32$.

17. Langfort J, Barańczuk E, Pawlak D, Chalimoniuk M, Lukacova $\mathrm{N}$, Marsala J, Górski J. The effect of endurance training on regional serotonin metabolism in the brain during early stage of detraining period in the female rat. Cell Mol Neurobiol. 2006;26(7-8):1327-42.

18. Michnik A, Drzazga Z. Thermal denaturation of mixtures of human serum proteins-DSC study. J Therm Anal Calorim. 2010;101:513-8.

19. Kosa T, Maruyama T, Otagiri M. Species differences of serum albumins II. Chemical and thermal stability. Pharm Res. 1998;15:449-54.

20. Michnik A, Michalik K, Kluczewska A, Drzazga Z. Comparative DSC study of human and bovine serum albumin. J Therm Anal Calorim. 2006;84:113-7.

21. Hodosy J, Ostatniková D, Cagánová M, Kovácsová M, Mikulajová M, Guller L, Putz Z, Celec P. Physical activity induces depression-like behavior in intact male rats. Pharmacol Biochem Behav. 2012;101:85-7.

22. Michnik A. Thermal stability of bovine serum albumin DSC study. J Therm Anal Calorim. 2003;71:509-19.

23. Donsmark M, Langfort J, Holm C, Plough T, Galbo H. Regulation and role of hormone-sensitive lipase in rat skeletal muscle. Proc Nutr Soc. 2004;63:309-14.

24. Langfort J, Jagsz S, Dobrzyn P, Brzezińska Z, Kłapcińska B, Galbo H, Gorski J. Testosterone affects hormone-sensitive lipase (HSL) activity and lipid metabolism in the left ventricle. Biochem Biophys Res Com. 2010;399:670-6.

25. Hagenfeldt L, Wahren J. Turnover of free fatty acids during recovery from exercise. J Appl Physiol. 1975;39:247-50.

26. Fujioka M, Shinohara Y, Baba S, Irie M, Inoue K. Acute suppression of endogenous testosterone levels by exogenous testosterone in normal men. Life Sci. 1987;41:945-9.

27. Anderson RA, Wallace AM, Kickman AT, Wu FCW. Comparison between testosterone oenanthate-induced azoospermia and oligospermia in a male contraceptive study. IV. Suppression of endogenous testicular and adrenal androgens. Hum Reprod. 1997;8:1637-62.

28. Sadowska-Krępa E, Kłapcińska B, Jagsz S, Sobczak A, Chrapusta SJ, Chalimoniuk M, Grieb P, Poprzęcki S, Langfort J. High-dose testosterone propionate treatment reverses the effects of endurance training on myocardial antioxidant defenses in adolescent male rats. Cardiovasc Toxicol. 2011;11:118-27.

29. Zieliński J, Kusy K. Training-induced adaptation in purine metabolism in high-level sprinters vs. triathletes. J Appl Physiol. 2012;112:542-51.

30. Dzeja P, Terzic A. Adenylate kinase and AMP signaling networks: metabolic monitoring, signal communication and body energy sensing. Int J Mol Sci. 2009;10:1729-72. 